\title{
Improving negotiation success in B2B sales organizations: is structured negotiation management a success factor?
}

\author{
Markus Mayer $^{1}$ (D) Markus Voeth $^{1}$
}

Accepted: 19 June 2021 / Published online: 2 August 2021

(c) The Author(s) 2021

\begin{abstract}
Researchers and practitioners alike recognize the necessity to manage salespeople before, during, and after negotiations. Literature identifies four approaches that companies use to manage salespeople in and around negotiations. However, it has never been researched which of these approaches help companies implement negotiation management successfully. The present study examines which management approach or combination of approaches lead to a consistently high level of negotiation success. The authors use a fuzzy-set qualitative comparative analysis to identify the conditions explaining negotiation success. The findings indicate that any effort to actively manage negotiations as a corporate capability supports sales in achieving a higher level of negotiation success. While the study was not able to identify any necessary conditions, the sufficient solution formula to reach a high level of negotiation success comprises two paths in its most parsimonious form. Following this solution formula, companies should either enable salespeople to solve complex situations autonomously and provide guidance along the negotiation process or define clear objectives, manage salespeople against deviations from the objectives, and monitor them closely throughout the negotiation process. This suggests, that successful negotiation management either empowers salespeople to act autonomously or focuses on a control management style. The latter should comprise both aspects of outcome and behavior control.
\end{abstract}

Keywords Negotiation management $\cdot$ Negotiation success $\cdot$ Sales $\cdot$ Salesforce control $\cdot$ Implementation

Markus Mayer

markus.mayer@simon-kucher.com

Markus Voeth

voeth@uni-hohenheim.de

1 Universität Hohenheim, Institut Für Marketing and Management, Lehrstuhl Für Marketing and Business Development, Fruwirthstraße 32, 70599 Stuttgart, Germany 


\section{Introduction}

With the ever increasing pressure to improve profitability, more and more companies have begun shifting their focus from optimizing procurement and production costs to improving the sales and pricing side of the profit equation (Simon et al. 2006). B2B businesses primarily close deals through negotiations (Movius and Susskind 2009; Grewal et al. 2015; Geiger 2017). Therefore, if companies want to excel, they need to pay attention to how their negotiations are conducted.

The topic of negotiation management has been receiving more attention in recent years. For example, practitioners have reported implementing negotiation units in their organizations (Ertel 2003), and scholars have presented frameworks to structure the preparation, conduct, and follow-up of business negotiations (Ertel 2003; Movius and Susskind 2009; Voeth and Herbst 2015). Despite the impressive body of literature on negotiation and salesforce control, the academic discussion too often focuses on the perspective of participants in negotiations and neglects to acknowledge that the company that mandates a salesperson to negotiate on its behalf is economically responsible for the deal (Dubinsky and Ingram 1984; Anderson and Huang 2006). Analyses that do go beyond the perspective of negotiators tend to investigate single issues, such as monetary incentives (Zoltners et al. 2012), overlooking the fact that companies have many more powerful levers to influence salespeople (Mahaney and Lederer 2011).

To emphasize this gap in literature, we highlight the work of Geiger (2017). Geiger (2017) presented a model discussing which tactics should be chosen to successfully close a deal in a B2B sales negotiation. While the choice of a certain tactic is relevant for a specific negotiation, the research question falls short on answering which management approach companies should follow to ensure that salespeople choose the right tactic for all negotiations. Generally, little has been researched on addressing negotiations as a corporate capability and the ways this influences success. The consultancy Huthwaite (2009) issued an external-view research report stating that companies with a more mature approach to negotiations observe stronger EBIT developments than those with a less mature approach to negotiations. However, this study did not investigate how companies operationalize negotiation management and how this operationalization approach influences negotiation success. In an attempt to close this gap in the academic discussion, Voeth and Mayer (2018) identified four conceptual approaches to implementing negotiation management within organizations. These are "enabling," "process guidance," "process control," and "manage by exception." These approaches each represent a typical set of levers companies utilize to influence salespeople. While partially the same levers can be used in different approaches, the operationalization of each will differ. However, due to the nature of their sample, Voeth and Mayer were not able to address the most interesting question, namely the extent to which the application of these approaches would help companies realize higher levels of negotiation success.

Therefore, this study attempts to determine the extent to which a structured approach to negotiation management supports higher levels of negotiation 
success. This insight will be pivotal for formulating recommendations on how to implement negotiation management in sales organizations. The two main research questions investigated are: First, if structured negotiation management helps to achieve better negotiation results? And second, if so, how should companies approach negotiation management to ensure achieving higher levels of negotiation success?

After this introduction, the authors will discuss the current status of the academic discourse on the topic. This section covers the perspectives of agency and salesforce control theory as well as the research on negotiation management to provide a foundation for the topic. Then, we will introduce Voeth and Mayer's (2018) approaches for implementing negotiation management and discuss the measures for identifying negotiation success. Afterwards, we will explain the research process, method, and calibration and analyze the success effect of the approaches on negotiation success using a fuzzy-set qualitative comparative analysis (fsQCA) and descriptive statistics. Finally, we will summarize the conclusions of the study, discuss limitations, and develop questions for future research.

\section{Status of academic discourse}

\subsection{Negotiation management}

Negotiation management research has evolved from the research on negotiations (Nyhart and Samarasan 1989) as a reaction to an overly focus on the perspective of negotiators in negotiation research (Ertel 2003; Anderson and Huang 2006; Williams and Plouffe 2007). In addition, negotiation management research acknowledges that it is the company that bears the economic risk of success or failure of a negotiation (Lewicki et al. 2014). As this paper focuses on sales negotiations, the understanding of negotiation management in this study will build on the definition provided by Eidenmüller (2012), who considers negotiation management to be "any conscious form of influencing salespeople along the negotiation process aiming to increase negotiation success." With that, Eidenmüller (2012) underlines the necessity of managerial actions. His understanding of sales negotiations as a discipline that can and should be influenced by managers is what sets it apart from the more tactical perspective in negotiation research, which has primarily investigated how to excel in negotiations (Ertel 2003). While few companies invest in meaningful negotiation training (Gates 2006; Movius and Süsskind 2009), even fewer appoint a negotiation manager or set up a dedicated preparation process (Ertel 2003; Herbst 2009; Huthwaite 2009; Voeth and Herbst 2015). What's more, most companies leave it to the salespeople to decide how to prepare and conduct sales negotiations and, consequently, only track negotiation outcomes.

This approach to negotiations results in suboptimal outcomes (Thompson 2005), which might be due to very diverse skill levels in the salesforce (Voeth and Herbst 2015).

To improve negotiation performance, researchers have presented different frameworks for managing negotiations that reflect the procedural nature of sales 
negotiations (Movius and Susskind 2009; Voeth and Herbst 2015). The frameworks all focus on directly influencing salespeople in negotiations but ignore that with rules, procedures, and systems companies have manifold indirect levers they can use to influence salespeople around negotiations. Ertel (2003), for example, suggests designating a negotiation officer to support sales in preparing and conducting negotiations. This move would have an impact on many negotiations, not just one. Like appointing a negotiation officer, companies could utilize countless measures to influence their salespeople indirectly before, during, and after negotiations.

In addition, negotiation management research focuses on different topics than salesforce control literature does. The latter mostly covers indirect management systems, such as monetary incentives (Eisenhardt 1985; Zoltners et al. 2012), and seldom discusses levers of direct influence. Interestingly, both streams of literature focus their argumentation on one end of the continuum between outcome-control and behavior control strategies (Anderson and Oliver 1987). This similarity was recognized by Voeth and Mayer (2018), who investigated levers that companies can use to directly and indirectly influence salespeople in the negotiation context and analyzed how companies combine them in practice. Based on the investigation of 27 potential levers and determining which were frequently applied together, they identified four approaches companies use in negotiation management: "manage by exception," "enabling," "process guidance," and "process control." These four approaches can each be understood as a set of levers to influence salespeople.

While the same levers can be used to influence salespeople in different approaches, they are operationalized differently. For example, training in a "manage by exception" approach would focus on explaining the rules, but in a "process guidance" environment, training would involve demonstrating how to use the tools provided.

As discussed in salesforce control theory, managers can either try to influence salespeople's behavior with specific instructions or define outcomes they expect and leave it to the salesperson to decide how to realize these targets (Anderson and Oliver 1987; Voeth and Mayer 2018). Consequently, management approaches will vary in terms of the orientation toward behavior or outcome control. This is a parallelism to sales force control theory, where Anderson and Oliver (1987) introduced the idea of a continuum of control strategies for salespeople, with the antipodes being behavior and outcome control. Most researchers, however, agree that the extremes do not exist in reality; rather, companies use a combination of control strategies (Anderson and Oliver 1987; Cravens et al. 1993; Zoltners et al. 2012).

Consequently, it seems logical that companies would select different approaches depending on the market situation or target. While it might be more effective to give negotiators minimal decision authority in a very transactional business, it could be necessary to allow them a high level of decision authority in relational businesses (Darmon and Martin 2011). A company might, for example, choose to give its salespeople much more freedom for large project offers or key accounts than it would for over-the-counter business with smaller customers. Similarly, a company might choose a different approach to negotiation management if it wanted to grow its market share than if it wanted to protect high price levels in the market (Hayter 2010). 
Therefore, the dimensions defining negotiation success also need to be considered when discussing the impact of negotiation management in sales.

In the next section, we will explain the four management approaches for introducing negotiation management with reference to the control strategy associated with them.

\subsection{Approaches for implementing negotiation management}

As explained in the previous section, Voeth and Mayer (2018) derived four approaches to negotiation management from 27 levers that companies can use to influence salespeople before, during, and after sales negotiations. Despite differences between recurring patterns in the lever use, which were translated into these four approaches, obviously certain levers are addressed by all companies regardless of the approach they follow. This observation seems quite natural, as, for example, most companies have some sort of pricing guidelines in place. However, it is the combination of these levers and their intended use that make up the different approaches. As such, the approaches described by Voeth and Mayer (2018) neither claim to be mutually exclusive nor collectively exhaustive. Rather, they offer orientation from a management perspective and can therefore be compared to management approaches.

The first approach that is described by Voeth and Mayer (2018) is the "manage by exception" approach (EXCEP). It is characterized by minimum managerial intervention in salespeople's decisions during the negotiation process as long as they operate in clearly defined boundaries. A company applying this management approach to negotiations would most likely put strict discounting policies and escalation procedures in place. If a salesperson wanted to close a deal beyond their decision authority, they would need to receive upfront managerial approval. The main building blocks of this approach are to define a clear pricing policy, commercial terms and conditions, establish escalation levels and procedures, instruct salespeople on these policies, and implement control mechanisms to ensure compliance with the defined policy. This approach does not involve influencing salespeople on how they prepare, conduct, or follow up sales negotiations as long as they adhere to the individual room for negotiation. Such an approach could be appropriate for individual deals whose value does not reach a critical size for the selling party or for companies aiming to have very lean and low-cost sales processes. Consequently, this approach might be most relevant if efficiency is a priority. Comparing this approach to the control and commitment management styles as described by Walton (1985), Koopman (1991), and Sull (2003) suggests the "manage by exception" approach follows a control idea. More specifically, this approach seems to tend toward the outcome control concept presented by Anderson and Oliver (1987).

The second approach discussed is the "enabling" approach (ENAB). It is characterized by the assumption that salespeople face a complex situation during negotiations and need to remain flexible to adapt their decisions and achieve the best possible results. Therefore, this approach focuses on having the right organizational structures in place to support salespeople in these "complex situations" and 
using variable monetary incentives to ensure salespeople's interests are congruent with company targets. In this context, the levers used to influence salespeople are mostly of indirect nature. A company following this management approach would be expected to focus on training its salespeople to understand drivers of complexity and aspects that create value for customers, having senior salespeople mentor more junior negotiators, and facilitating the exchange of lessons learned among sales teams. Such an approach seems appropriate for sales processes with a high degree of freedom, for example when the product is being developed or modified according to customer needs during the selling process. The high degree of freedom provided to salespeople with this approach could be beneficial for companies that want to grow their footprint in the market or develop new business. With these objectives, outcomes are often more important than how they are achieved, which implies effectiveness could be of particular interest. On the other hand, the commitment required from salespeople to develop and execute actions to reach this goal positions this approach toward a commitment-oriented management style, as described by Koopman (1991).

The third approach is "process guidance" (GUIDE). This approach involves supporting salespeople throughout the process of preparing, conducting, and following up sales negotiations. In addition to a clear pricing policy and well-defined trade terms, salespeople are provided with support tools for the negotiation process. Managers can ensure goal orientation by aligning with salespeople during the negotiation and facilitating the exchange of lessons learned afterward. Contrary to the "manage by exception" approach, managerial action aims at supporting salespeople throughout the entire negotiation process to reach the best possible negotiation results. This management approach might be appropriate in situations where there is wide variation between different deals. If deals in such a setting reach a critical size, companies might want to enforce certain standards for the negotiation preparation or involve a specialist. In some companies, this approach might even involve introducing a supporting role such as a dedicated negotiation management function (Ertel 2003). Similarly to the "enabling" approach, "process guidance" is less focused on control and restrictions for salespeople, which may result in higher satisfaction among salespeople and imply this approach belongs to the group of commitment-oriented management styles (Walton 1985). However, the orientation provided throughout the negotiation process could indicate that more focus is put on efficiency.

The fourth approach discussed is "process control" (CONTR). It involves defining every step of the negotiation process, providing tools to solve the challenges of each step, and closely monitoring for compliance to the defined actions, policies, and procedures. In addition to defining a clear policy and trade terms, providing support tools, and enforcing feedback loops, this approach puts a strong focus on steering salespeople's actions throughout the negotiation process (Anderson and Oliver 1987). The use of such an approach to negotiation management could be fitting for sales processes that are rather deterministic and require very limited creativity from salespeople. With this approach, managers are expected to have a thorough understanding of salespeople's activities in order to set activity targets. Salespeople are responsible for executing the defined activities but are not directly responsible for reaching revenue or profit targets. "Process control" involves the highest level of 
managerial activity out of the four approaches, which implies that companies following this approach care about how they achieve their results. In line with this assumption, Voeth and Mayer (2018) position this approach closest to behavior control in the Anderson and Oliver (1987) continuum.

To provide a better understanding of the approaches and their specificities, Table 1 highlights lever combinations associated with each.

\section{Research question}

To date, negotiation management literature has not sufficiently addressed whether the application of a structured negotiation management helps sales organizations regularly achieve better negotiation results. However, this question is important from the perspective of both researchers and practitioners. Researchers have highlighted examples where introducing negotiation management has led to positive effects (Ertel 2003; Movius and Susskind 2009). However, these cases do not allow for a general statement to be made on whether structured negotiation management increases negotiation success, which is the ultimate measure for determining whether managing negotiations is meaningful (Keeney et al. 2003; Halpert et al. 2010). If the answer to this question is yes, only then can the call for structured negotiation management be justified (Nyhart and Samarasan 1989; Ertel 2003; Movius and Susskind 2009). More precisely, two questions need to be differentiated in this respect: First, does applying negotiation management make sense in general? A first positive answer has been indicated by Huthwaite (2009). As mentioned, the Huthwaite study came to this conclusion without relating it to how companies operationalize negotiation management from an internal perspective. The findings therefore provide limited orientation for managers, since they do not provide guidance on how to implement negotiation management within the organization.

The second question must be: How should companies apply negotiation management to actually improve negotiation success? If one of the four abovementioned strategies or a combination of them were found to result in higher levels of negotiation success, this insight would provide managers with guidance on how to set up negotiation management within their organizations.

A confirmation of the first research question does not necessarily imply its opposite, i.e., that not applying negotiation management results in low negotiation success. While it may help a sales organization to have, for example, detailed support tools and checklists for negotiation preparation, salespeople do not necessarily fail in negotiations if they do not receive this kind of support. Due to this assumption of causal asymmetry, this study will analyze the results using the method qualitative comparative analysis (QCA) (Ragin 1987, 2008b; Ragin and Rihoux 2009; Schneider and Wagemann 2013). More important than causal asymmetry, the equifinality in sales and negotiation situations also makes the use of QCA appropriate. The term equifinality means that there is more than one way to achieve negotiation success (Ragin 1987, 2008b; Ragin and Rihoux 2009; Schneider and Wagemann 2013). Two companies in the same setting might both have successful negotiations but apply very different approaches to negotiation management. 


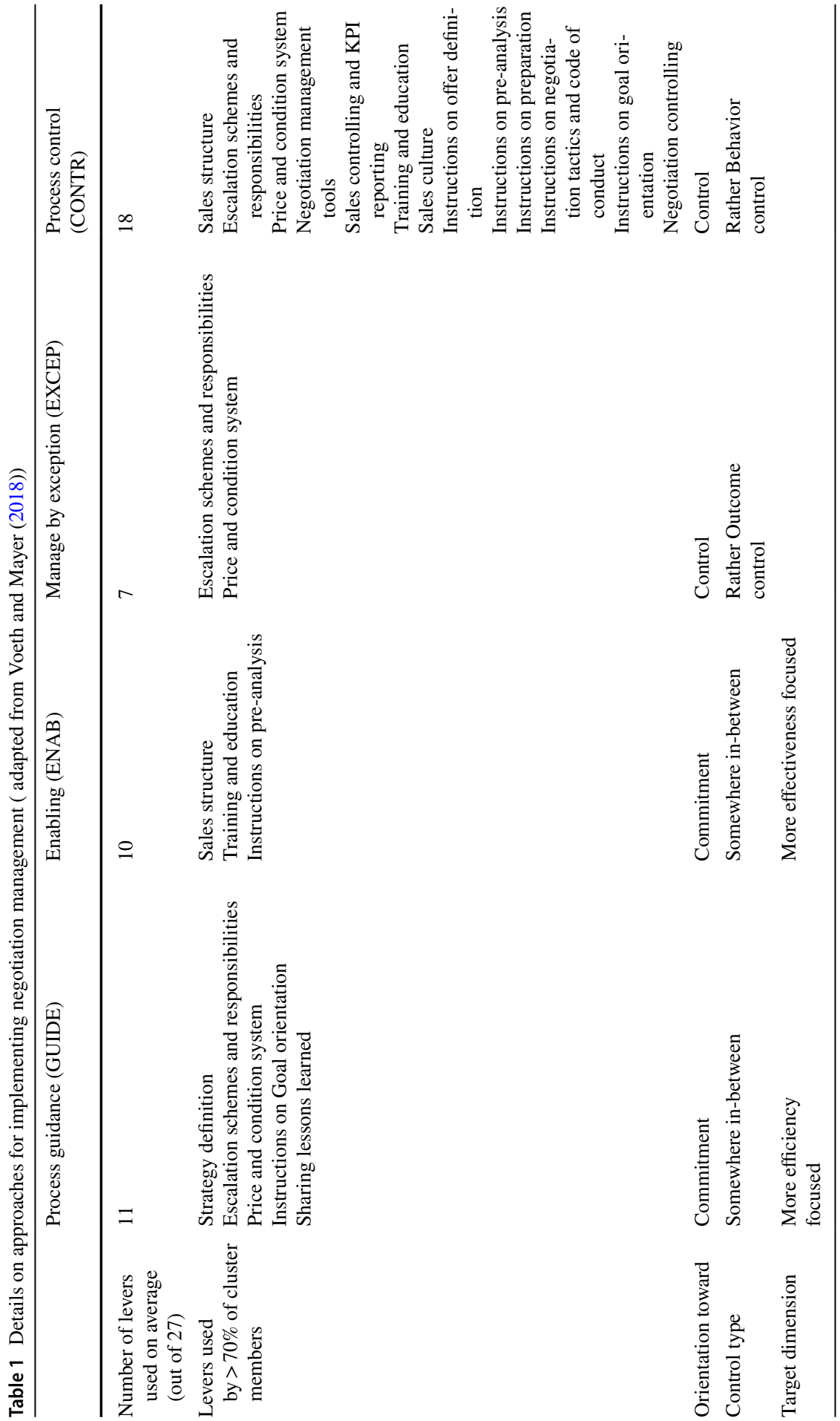


In summary, the main research questions are: Is managing negotiations in a structured way beneficial or not? More precisely, does negotiation management help companies achieve higher levels of negotiation success, and if so, how is it beneficial? Since negotiation success is not an established term, we will summarize the current academic discussion in the next section.

\subsection{Measuring negotiation success}

Success in negotiations can be discussed along three dimensions. The most obvious dimension for a selling party is to reach a deal at the highest possible sales price, meaning effectiveness. Since the magnitude of negotiation management also induces costs for an organization, the second aspect is how a deal is reached, meaning efficiency. Third is the motivation of salespeople in negotiations, which is often discussed in literature (De Dreu 2004). This line of argumentation posits that unmotivated salespeople likely do not put in their best effort during negotiations and, as a result, do not achieve great outcomes (Giangrecco and Peccei 2005). Consequently, the third dimension relates to the satisfaction with the negotiation and results.

These three dimensions can also be found in different streams of research concerning negotiation success. In the first stream, Keeney, Raiffa, and Meyer (2003) argue for an objective measurement of negotiation performance using the achievement of objectives. These metrics are either directly expressed as financial measures (Zetik and Stuhlmacher 2002; Kurtzberg et al. 2005), connected to the number of targets (Gaibulloev and Sandler 2009), or computed as an abstract utility (Burkardt et al. 1998; O'Connor et al. 2005; Melzer and Schoop 2016). Within this stream, a second group of authors (Thompson 1990; Kray and Thompson 2005; Imai and Gelfand 2007) emphasizes the distinction between distributive and joint outcomes, as introduced by Fisher et al. (2012). While distributive negotiation is characterized by tradeoffs within a fixed set of utility, integrative negotiations increase the pie to be distributed by identifying mutual gains in negotiation targets (Thompson 1990). The dimensions effectiveness, efficiency, and satisfaction correspond to the separation of selling and non-selling sales activities in the academic discussion on sales performance. While selling activities directly influence measurable performance key performance indicators (KPIs), non-selling activities are expected to positively influence future sales results (Cravens et al. 1993). This underlines that solely focusing on financial results might lead to a company to falling short on important dimensions of negotiation success.

The second stream of research therefore defines negotiation success in a broader sense. Halpert et al. (2010) conducted a meta-analysis to identify drivers of negotiation success. In addition to the "profit or loss outcome of the negotiation, [they identified] the negotiator's perceptions of the other party and the negotiator's satisfaction with the negotiation" as key drivers of negotiation success. This model was applied and tested by Fells (2013), who concluded that, despite the relevance of the perception and satisfaction dimensions, the substantive profit dimension of success counts most. The satisfaction dimension and the perception of the other party are both immaterial outcomes and can be interpreted as influencing factors of the 
future relationship between the negotiating parties. Approaching the same question from a different angle, Lim and Carnevale (1990) conducted a factor analysis to find drivers of success in the mediation of disputes. Combining different attributes, they identified three major drivers: general settlement, mediator outcomes, and improved relationship. Comparing this finding to the results of Halpert et al. (2010) and the previous discussion, joint dimensions seem to emerge. A first dimension covers the effectiveness of a negotiation, meaning the extent to which negotiation targets are reached. A second dimension reflects the impact of negotiations on an ongoing relationship. Assuming that an improved relationship with the customer eases the process of future negotiations, this second dimension can be understood as negotiation efficiency. Underdal (1983), Allred et al. (1997), and Amantullah and Tinsley (2013) support this conclusion, as they use the same two dimensions in their research. Alexander et al. (1994), Schoop et al. (2010), and Voeth et al. (2014) apply the same criteria but add the afore-discussed third dimension covering negotiation satisfaction, assuming that negotiators' satisfaction will result in higher intrinsic motivation. This assumption has been confirmed to have a positive effect on negotiation outcomes by Homburg et al. (2012) and Zoltners et al. (2012).

While all three dimensions constitute relevant aspects of negotiation success, it would also be interesting if a specific approach to the implementation of negotiation management were particularly powerful in supporting specific success dimensions. It seems possible that, for example, approaches on the behavior-control side ("process guidance" and "process control") helped improve effectiveness but limited satisfaction and vice versa for the outcome-control-oriented approaches ("enabling" and "manage by exception").

\section{Methodology}

This study utilizes the method fuzzy-set qualitative comparative analysis (fsQCA) to identify if structured negotiation management has a positive impact on negotiation outcomes, if particular approaches should be used to ensure higher levels of negotiation success, and if certain approaches support specific dimensions of success. This choice of analysis method is due to the assumed causal asymmetry in the applicability of implementation approaches to negotiation management in different situations to foster negotiation success (Schneider and Wagemann 2013). In other words, while applying a specific approach to negotiation management might increase negotiation success, not applying this approach does not necessarily result in low levels of negotiation success. Similarly, fsQCA was chosen due to the assumed equifinality underlying negotiation management. This term means that more than one approach can lead to a high level of negotiation success (Schneider and Wagemann 2013). Two otherwise similar companies might choose different ways to implement negotiation management and both succeed in their negotiations. Methods such as regression analysis do not sufficiently account for this characteristic (Schneider and Wagemann 2013). In that sense, QCA can be seen as a good structure-detecting method. Once there is sufficient clarity on the drivers and causal relationships that explain 
negotiation success, the analysis should be extended with, for example, regression analytic considerations (Frösen et al. 2016).

As qualitative comparative analysis is a rather new research method, the next section will provide a brief introduction to the method. Then, the research process, sample structure, scales utilized, and model calibration will be explained. Lastly, the following section will discuss the results using descriptive measures and fsQCA.

\subsection{Fuzzy-set qualitative comparative analysis the method}

Qualitative comparative analysis (QCA) was initially presented by Ragin (1987) and extended to fuzzy-set QCA by Ragin (2000). Since then, it has been introduced to numerous fields of academic research (Fiss 2011; Tóth et al. 2015; Frösén et al. 2016; Werani et al. 2016). QCA is based on Boolean algebra and analyzes the presence and absence of conditions that are hypothesized to have an effect on the presence or absence of a desired outcome. Contrary to regression analysis, which tries to explain the extent to which each independent variable holds explanatory power toward the observed dependent variable, QCA focuses on identifying combinations of conditions in the presence or absence of the outcome (Schneider and Wagemann 2013; Schulze-Bentrop 2013). While regression analysis presumes a symmetrical effect toward a high level of correlation with the dependent variable, QCA does not make this assumption. Therefore, QCA does not simplify complex causalities like quantitative methods do (Ragin 1987; Schneider and Wagemann 2013) and allows for multiple combinations of conditions leading to the same outcome, otherwise known as equifinality (Fiss 2011; Schneider and Wagemann 2013). In particular, QCA identifies both necessary and sufficient conditions for the presence or absence of an outcome. A sufficient condition in this sense would be the presence of the outcome whenever the condition is present, and a necessary condition would be the presence of the condition whenever the outcome is present (Schneider and Wagemann 2013). To accept a necessary or sufficient condition, the consistency, coverage, and relevancy of the conditions must surpass certain minimum thresholds (Goertz 2006; Ragin 2006; Ragin and Rihoux 2009; Schneider and Wagemann 2013). Therefore, this method is helpful in investigating which operationalization approach or combination of approaches to negotiation management lead to high or low levels of negotiation success.

\subsection{Research process and sample structure}

The study was conducted as an online survey of professionals from three countries and two continents. They were approached via the B2B panel of Lightspeed Research (Lightspeed 2017). A total of 1254 respondents answered the questionnaire; of which, 109 had to be removed due to problematic answering patterns. The responses of the remaining 1145 respondents serve as the sample used in this research; of which, 701 answered all of the questions. Thus, out of the responses collected, 91.3 percent are included in the analysis. The questionnaire was online 
from July 17 to September 2, 2017 and took respondents, on average, $12 \mathrm{~min}$ to complete.

The respondents were salespeople (53 percent) or managers (27 percent) or filled other functions (20 percent) from the countries Germany (47 percent), the US (34 percent), and the UK (19 percent). Interestingly, no significant differences were observed in the responses from salespeople compared to those from managers. Respondents reported to represent service businesses (43 percent), trade businesses (38 percent), and manufacturing businesses (19 percent). With roughly the same share, respondents reported to focus on B2B, B2C, or a mix of B2B and B2C markets. The sizes of companies represented in the survey were distributed more or less equally in terms of annual sales, ranging from less than 100 thousand euros to more than one billion euros. The majority (93 percent) operate their own sales team and therefore do not outsource selling activity.

The application of the four approaches to implement negotiation management and the different dimensions of negotiation success as well as demographics were addressed in the questionnaire using a six-point scale from "fully applies" to "does not apply at all" as suggested by (Ragin 2000, 2007, 2008a,b, 2009; Schneider and Wagemann 2010, 2013; Tóth et al. 2015) (see Table 3). The fsQCA analysis was conducted using the software R with the packages QCA, QCAGUI, and QCAtools (Duşa and Thiem 2016). No quotas were applied to influence the structure of the sample.

The scale used to measure negotiation success was adapted from the scale introduced by Voeth et al. (2014). Scale items were slightly modified to elevate them from the perspective of salespeople and a single negotiation to the company perspective and multiple negotiations. The scale and constructs used to measure negotiation success (N_SUC) can be found in Table 2.

\subsection{Calibration process}

An integral part of QCA analysis is to logically investigate all items to determine whether they indicate set membership or non-membership (Schneider and Wagemann 2010, 2013). The application of each of the four approaches was calibrated to fuzzy-set membership with full inclusion for "applicability above average" and full exclusion for "applicability below average." This threshold was chosen because it provides the logical separation between applying and not applying an approach (Schulze-Bentrop 2013; Schneider and Wagemann 2013). Following the suggestion of Schneider and Wagemann (2010), the sensitivity of results to changes in the calibration was tested by conducting the fsQCA with full inclusion above "mostly applies" and full exclusion below "seldom applies." While the results remain identical, this reduces the level of consistency observed in the fsQCA (see Table 3).

In addition, the correlation between the four approaches was computed and can be found in Table 4. Rather low levels of correlation were identified between the approaches, meaning that they can all be considered distinct approaches. Cronbach's Alpha for the four approaches is 0.74 , which signals a good level of internal consistency. This observation is also supported by the high value for composite reliability 
Table 2 Constructs used

\begin{tabular}{|c|c|}
\hline Variable & Scale items \\
\hline \multicolumn{2}{|l|}{ Outcome } \\
\hline \multicolumn{2}{|l|}{ Negotiation success (N_SUC) } \\
\hline \multirow[t]{5}{*}{ Negotiation effectiveness (EFFEC) } & $\begin{array}{l}\text { Optimum results regarding financial KPIs (profit) are } \\
\text { reached. Deals fully support company strategy and } \\
\text { budgets }\end{array}$ \\
\hline & $\begin{array}{l}\text { The number and value of concessions in negotiations are } \\
\text { minimal. If necessary, concessions made follow a planned } \\
\text { pattern }\end{array}$ \\
\hline & $\begin{array}{l}\text { Negotiators reach the best possible agreements in the } \\
\text { respective situation }\end{array}$ \\
\hline & The results have a positive impact on future negotiations \\
\hline & $\begin{array}{l}\text { The desired deals are won and executed at a very high rate } \\
\text { (very low default rate) }\end{array}$ \\
\hline \multirow[t]{5}{*}{ Negotiation efficiency (EFFI) } & $\begin{array}{l}\text { Sales prioritizes the right deals, takes all necessary actions, } \\
\text { and focuses on the key aspects to reach an agreement }\end{array}$ \\
\hline & $\begin{array}{l}\text { All activities conducted to manage negotiations are neces- } \\
\text { sary to support sales in negotiations }\end{array}$ \\
\hline & $\begin{array}{l}\text { Customers perceive the negotiation team as professional due } \\
\text { to comprehensive preparation, professional appearance, } \\
\text { and structured approach }\end{array}$ \\
\hline & Agreements are reached as fast as possible \\
\hline & $\begin{array}{l}\text { Costs for reaching agreement (resources used and if so, how } \\
\text { is it beneficial to prepare for and over the course of the } \\
\text { negotiation) are as low as possible }\end{array}$ \\
\hline \multirow[t]{5}{*}{ Negotiation satisfaction (SATIS) } & Negotiation teams are satisfied with their performance \\
\hline & Negotiation teams are satisfied with the results \\
\hline & $\begin{array}{l}\text { Management is satisfied with the negotiation results. } \\
\text { (Management's expectations of negotiation results have } \\
\text { been met.) }\end{array}$ \\
\hline & Management is satisfied with the negotiators' performance \\
\hline & $\begin{array}{l}\text { Negotiations were close to the company's understanding of } \\
\text { an ideal negotiation }\end{array}$ \\
\hline
\end{tabular}

Conditions

Approaches for implementing negotiation management

Enabling approach (ENAB)

Salespeople have been trained to resolve complex situations themselves

Manage by exception approach (EXCEP) Little guidance is provided for the negotiation process; salespeople operate freely within narrow pricing boundaries

Process guidance approach (GUIDE) Salespeople are supported during the negotiation process Process control approach (CONTR)

A maximum amount of guidance and control occurs during the negotiation process through clear instructions, management of the process, tools, and close monitoring 


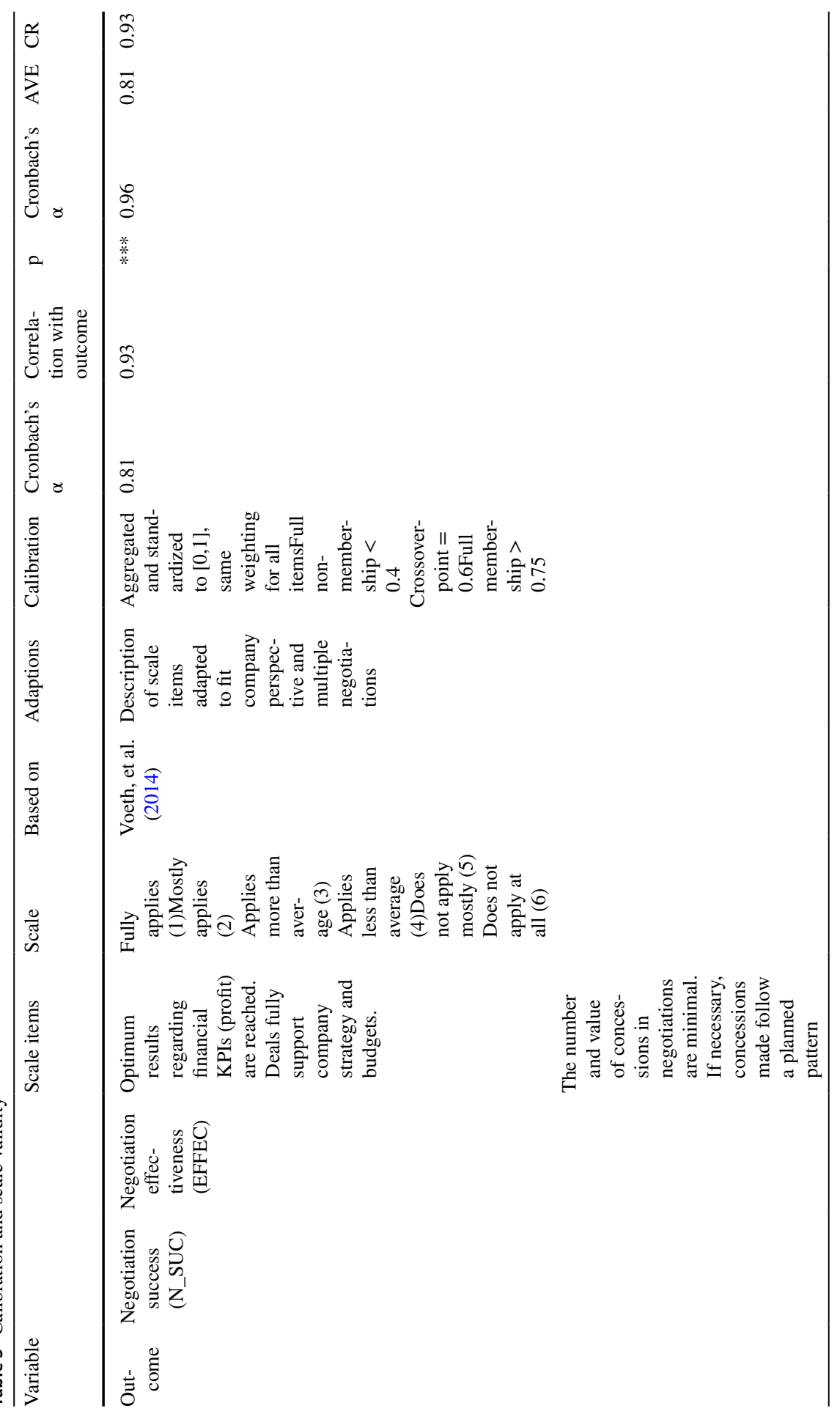




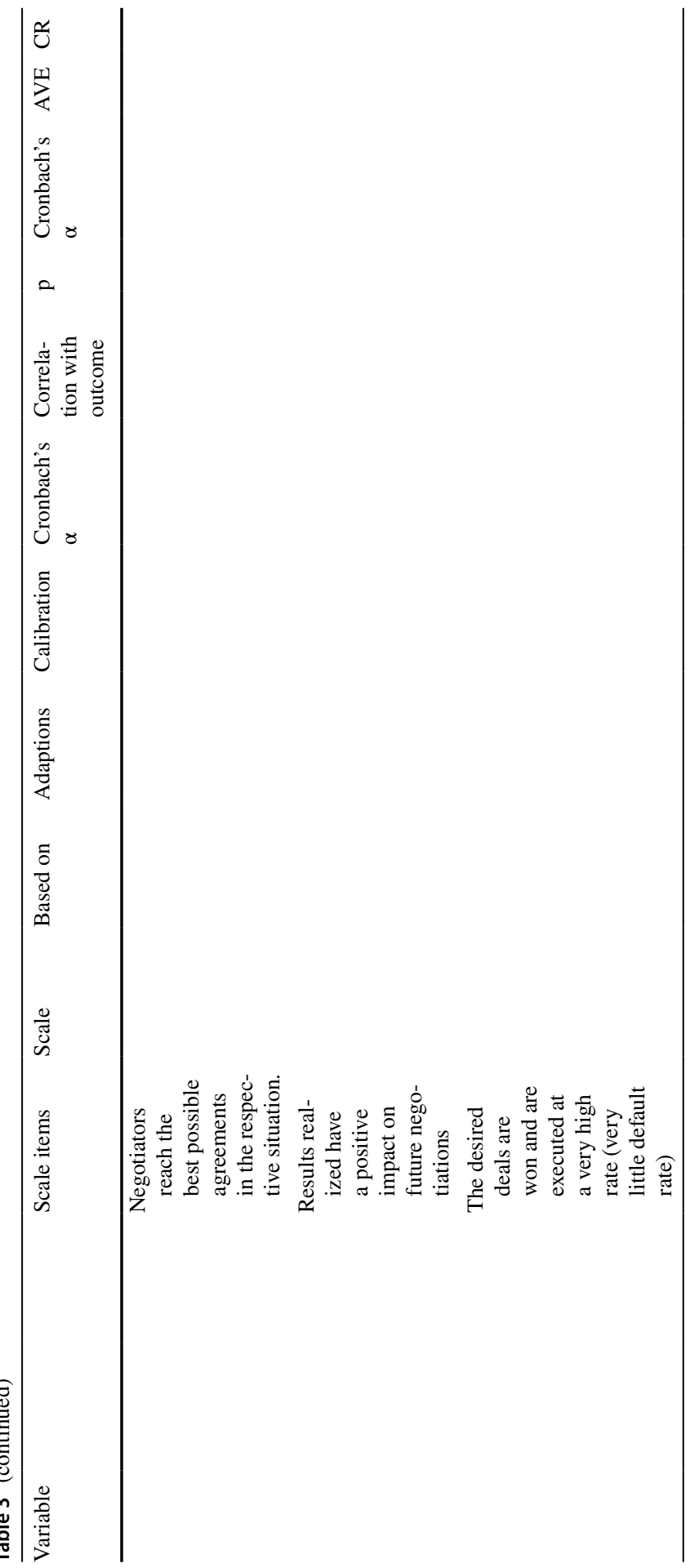




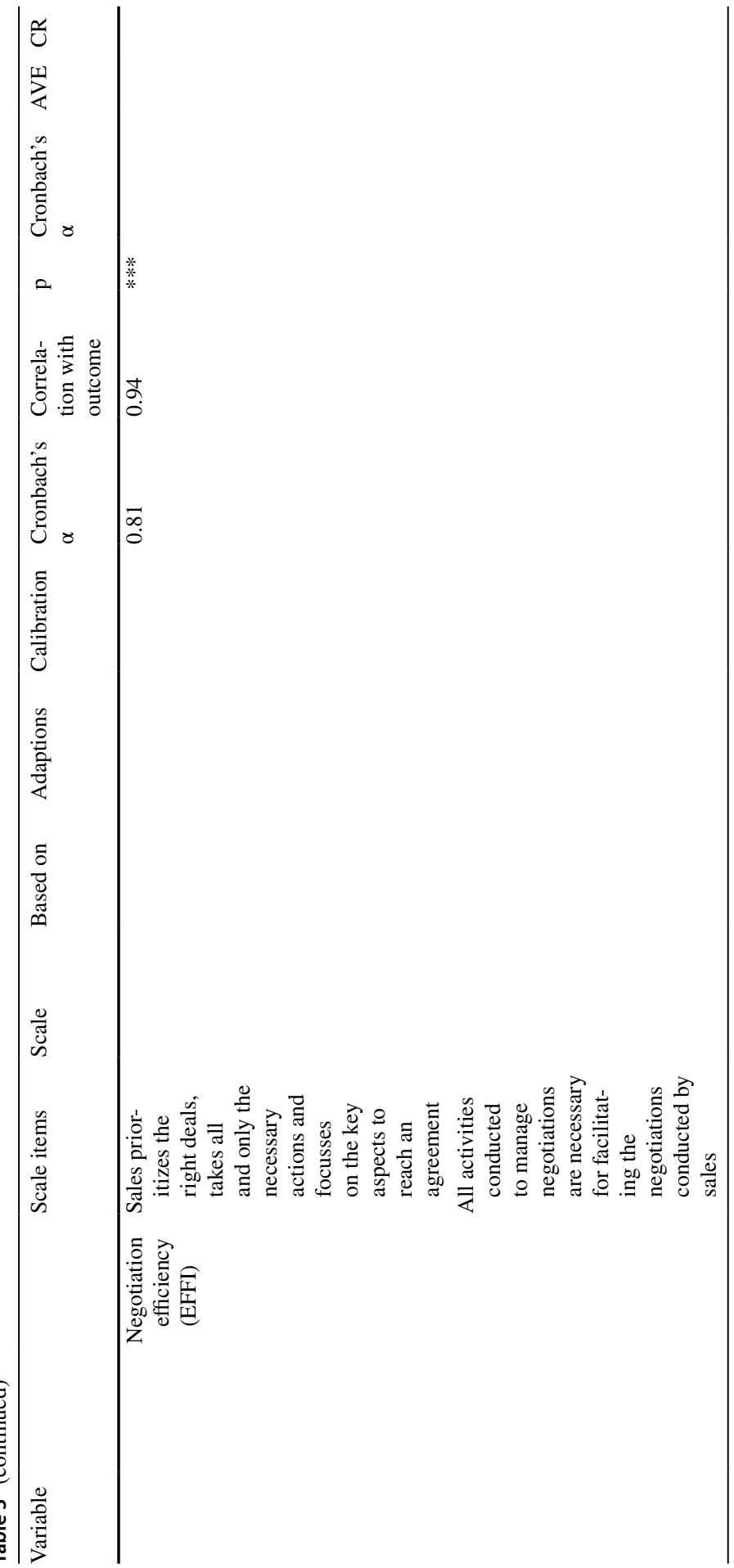




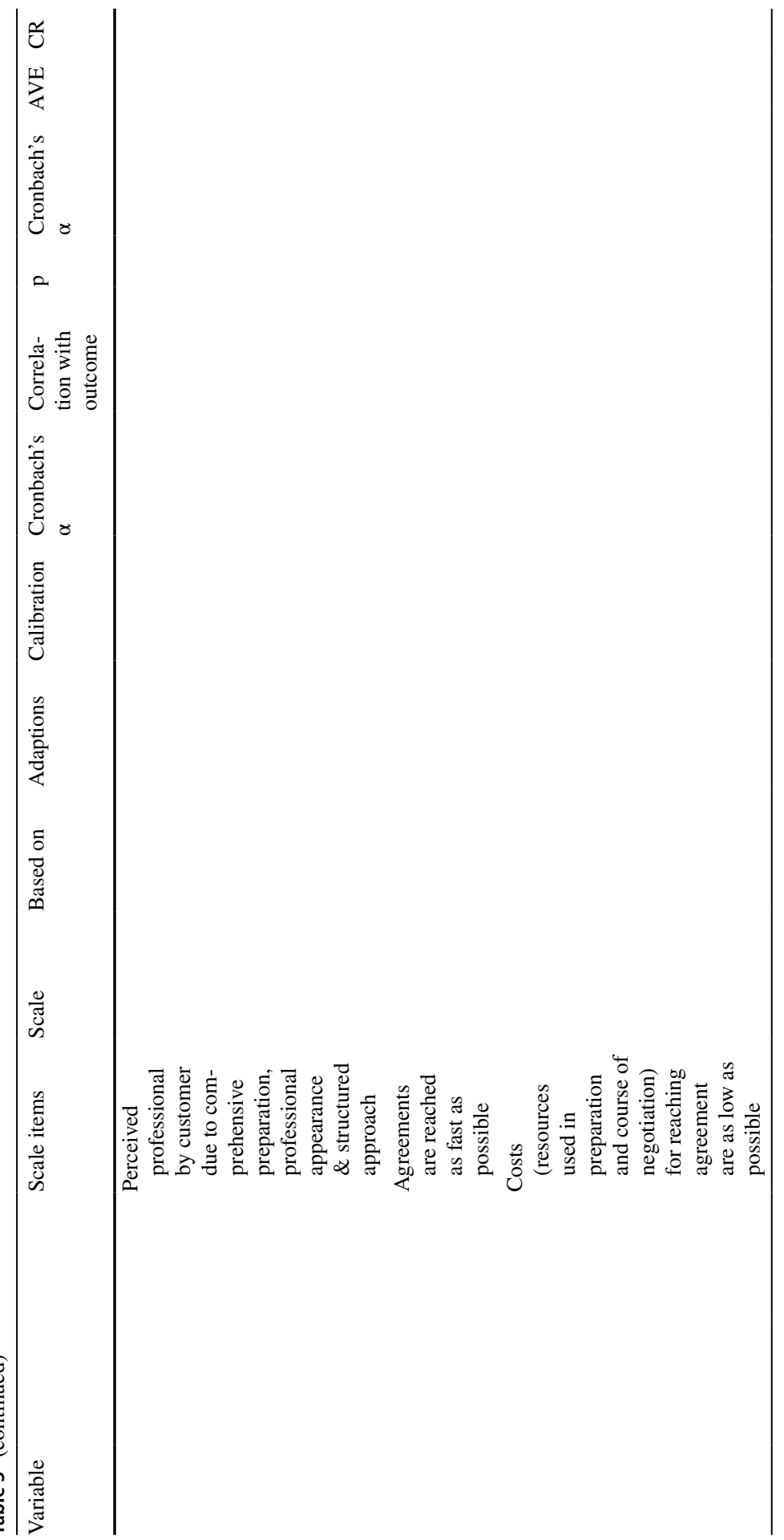




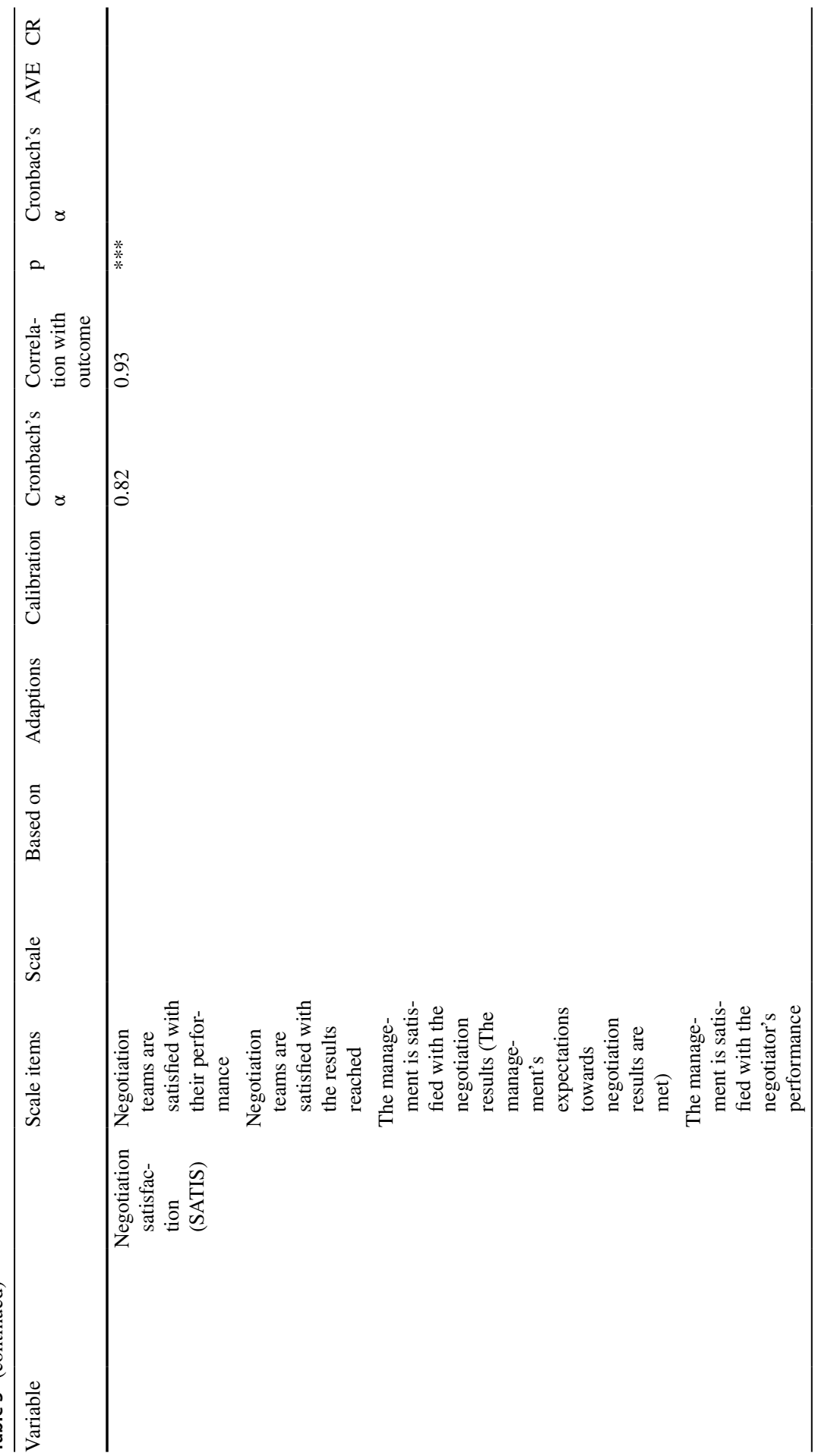




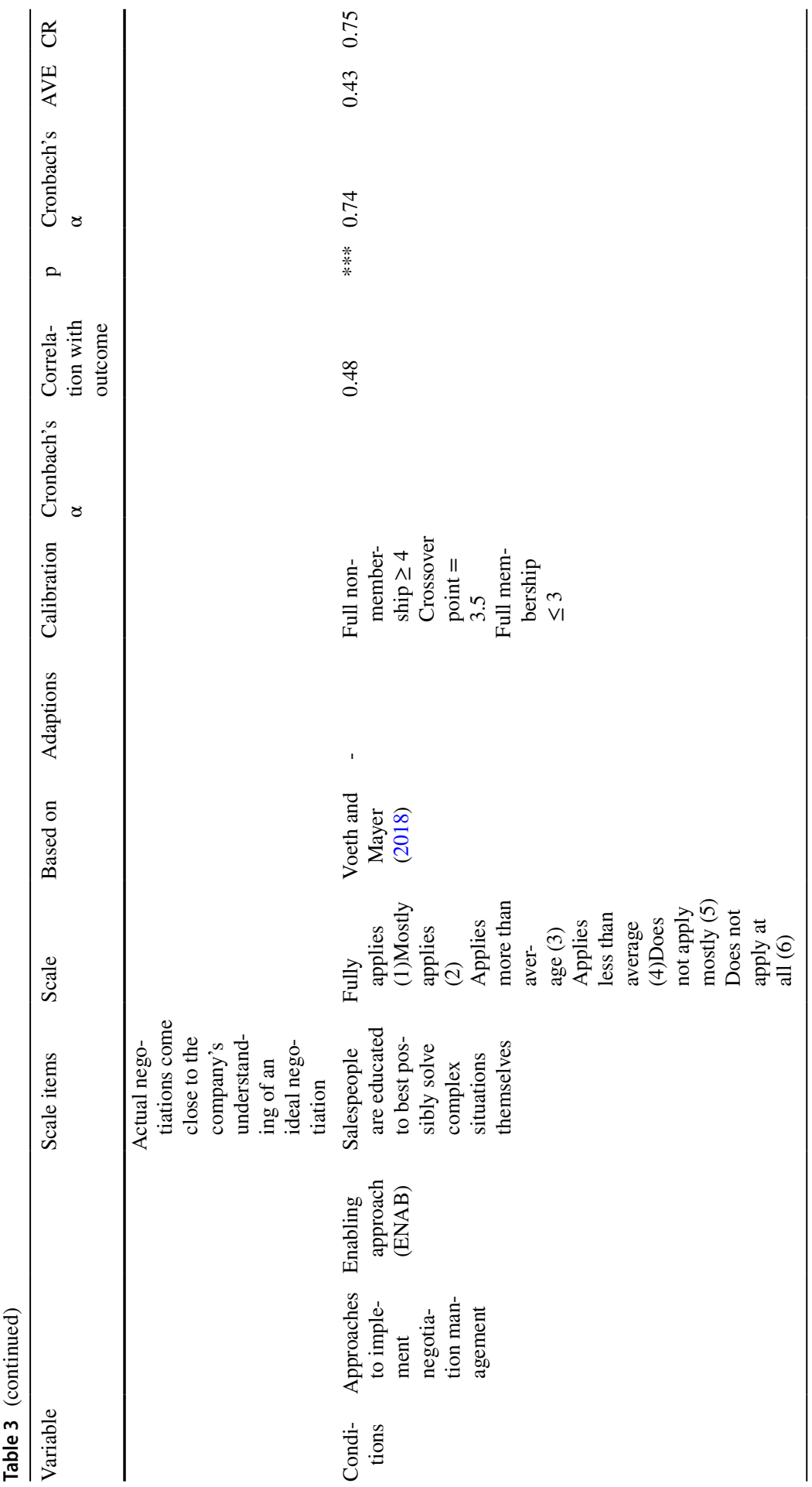




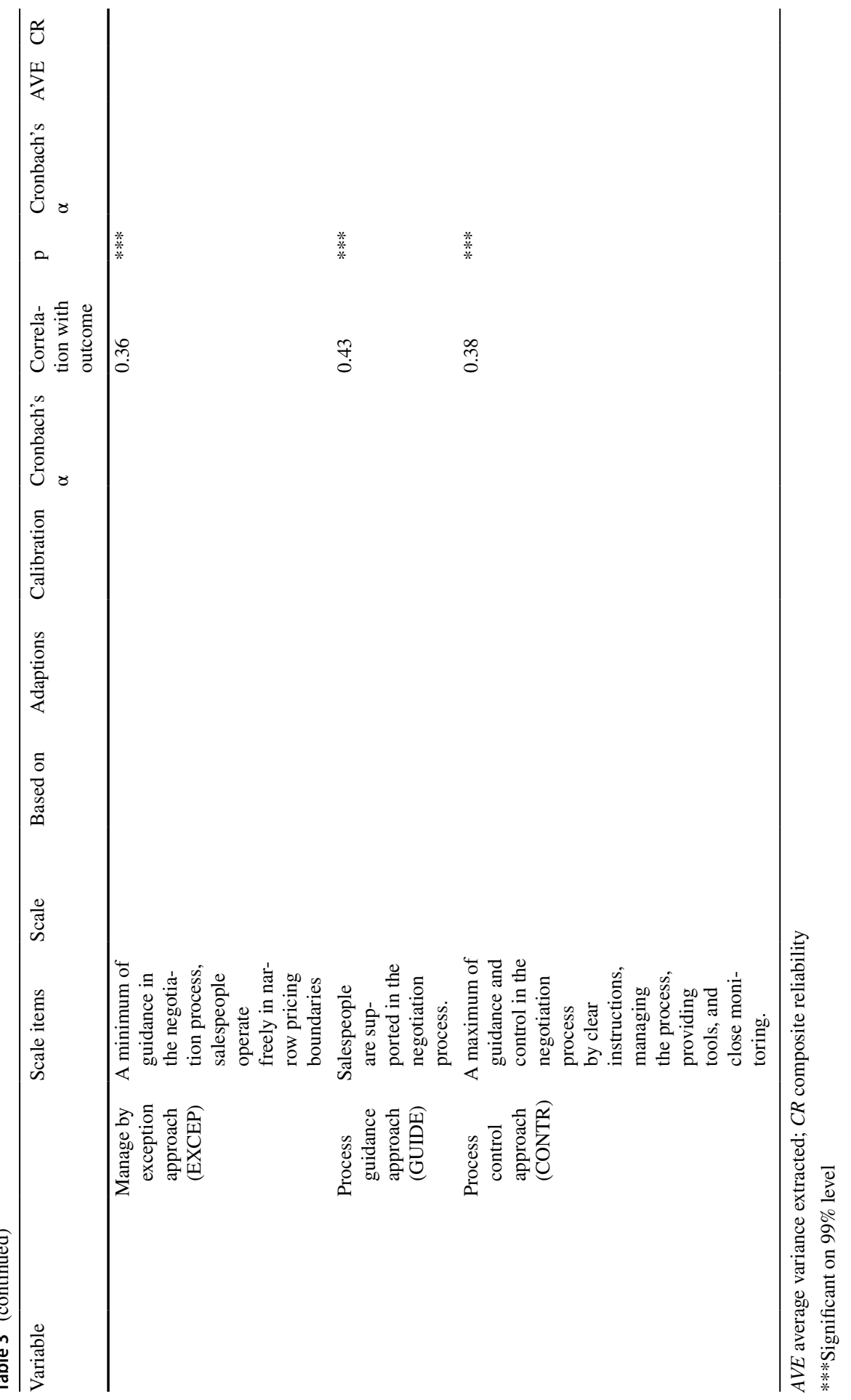


Table 4 Correlation of approaches for implementing negotiation management

\begin{tabular}{lllll}
\hline & ENAB & EXCEP & GUIDE & CONTR \\
\hline ENAB & 1.00 & & & \\
EXCEP & $0.45^{* * *}$ & 1.00 & & \\
GUIDE & $0.50^{* * *}$ & $0.40^{* * *}$ & 1.00 & \\
CONTR & $0.38^{* * *}$ & $0.25^{* * *}$ & $0.53^{* * *}$ & 1.00 \\
\hline
\end{tabular}

$* * *$ Significant on $99 \%$ level

(see Table 4). The distribution of reported negotiation success was skewed, likely due to respondents overestimating their own negotiation performance. The responses were calibrated for use in the fsQCA. After aggregating all items with equal weights, the threshold for full exclusion was set to 0.4 , the most ambiguous point for set membership to 0.6 , and the threshold for full membership to 0.75 , following the suggestion for calibration of set membership found in the literature (Ragin 2000, 2007; Fiss 2011; Frösén et al. 2016) (see Table 4). The guiding idea for choosing these thresholds was to ensure a relevant number of observations for set membership, non-membership, and in-between. For the success dimension, the sensitivity of the results of the fsQCA was tested. Changing the above thresholds for full inclusion and full exclusion for set membership within a 20-percent range does not change the results of the study. All calibrations were done using the "calibrate" function provided by the R-QCA package (Duşa and Thiem 2016). A high level of internal consistency (Cronbach's Alpha 0.96), average variance explained (AVE=0.81), and composite reliability $(\mathrm{CR}=0.93)$ could be found for the negotiation success scale, reinforcing the use of this in the context of negotiation management (see Table 4).

\section{Results discussion: are implementation approaches for negotiation management a success factor?}

\subsection{Descriptive analysis of results}

As companies can apply none, one, two, three, or all four approaches, there are 16 possible combinations. Table 5 provides an overview of how often respondents reported to apply none, one, or multiple approaches.

Table 5 contains the distribution of reported negotiation success for the number of different approaches applied. Notably, the average level of negotiation success increases with the number of approaches applied. This observation is supported by the correlation between negotiation success and the application of either none or all four of the approaches (see Table 5). While neither of the two correlations are high enough to explain negotiation success or failure alone, the positive value for the application of all four approaches and the negative value for not applying any approach, both significant on the 99-percentage level, provides further evidence for the hypothesis that any form of conscious negotiation management supports high negotiation success. However, the distribution of negotiation success seems wide, 


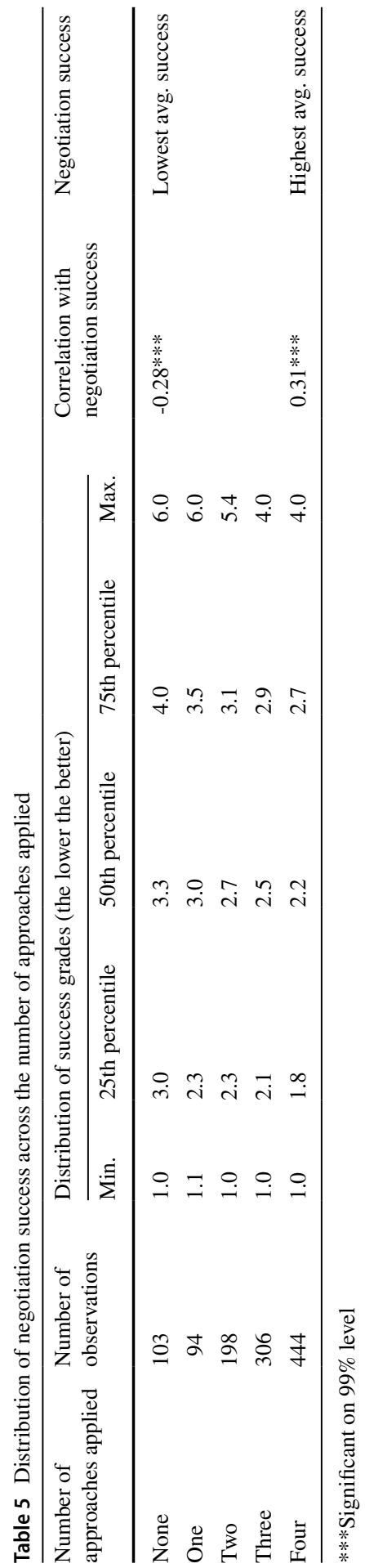


meaning that low and high levels of success can be found in observations where structured negotiation management is applied but also where it is not applied. This finding corresponds with the low though highly significant correlation of the four approaches with negotiation success (Table 5) and the low value of average variance extracted $(\mathrm{AVE}=0.43)$ (Table 5), which suggests two conclusions. On the one hand, it could be expected that the approaches for implementing negotiation management can only explain some elements of negotiation success, while other factors play a similarly important role. On the other hand, as it has been argued before that causal asymmetry and, particularly, equifinality are to be expected, which suggests the analysis using QCA.

\subsection{Discussion of fs $Q C A$ results}

\subsubsection{Analysis of necessary conditions}

Table 6 provides an overview of the values for consistency, relevance of necessity, and coverage for all four approaches for the presence of the outcome and was computed using the respective functions in the QCA package in R (Duşa and Thiem 2016). Noteworthy are the significantly higher values of consistency for the presence of the conditions (capital letters) toward the presence of the outcome compared to the absence of the conditions (lowercase letters). These results can again be interpreted as an indication that the approaches do have a positive effect on negotiation success. Nevertheless, the values observed do not surpass the commonly defined minimum threshold in the academic literature of 0.9 to accept either approach as a necessary condition (Ragin 2006, 2009; Schneider and Wagemann 2010, 2013). Consequently, none of the four approaches can be accepted as a necessary condition for a high level of negotiation success.

Configurations of the approaches leading to low levels of negotiation success, namely the absence of the outcome, may be very different from those explaining

Table 6 fsQCA necessary conditions

\begin{tabular}{|c|c|c|c|c|c|c|c|}
\hline \multirow{3}{*}{\multicolumn{2}{|c|}{ Condition }} & f necessary cc & ditions & & & & \\
\hline & & \multicolumn{3}{|c|}{ Presence of outcome } & \multicolumn{3}{|c|}{ Absence of outcome } \\
\hline & & \multirow{2}{*}{$\begin{array}{l}\text { Consistency } \\
0.707\end{array}$} & \multirow{2}{*}{$\begin{array}{l}\text { Relevance of } \\
\text { necessity }\end{array}$} & \multirow{2}{*}{$\begin{array}{l}\text { Coverage } \\
0.800\end{array}$} & \multirow{2}{*}{$\begin{array}{l}\text { Consistency } \\
0.532\end{array}$} & \multirow{2}{*}{$\begin{array}{l}\begin{array}{l}\text { Relevance of } \\
\text { necessity }\end{array} \\
0.423\end{array}$} & \multirow{2}{*}{$\begin{array}{l}\text { Coverage } \\
0.230\end{array}$} \\
\hline 1 & CONTR & & & & & & \\
\hline 2 & GUIDE & 0.776 & 0.699 & 0.810 & 0.542 & 0.360 & 0.216 \\
\hline 3 & EXCEP & 0.726 & 0.729 & 0.803 & 0.533 & 0.406 & 0.225 \\
\hline 4 & ENAB & 0.851 & 0.608 & 0.804 & 0.602 & 0.280 & 0.217 \\
\hline 5 & contr & 0.319 & 0.832 & 0.641 & 0.538 & 0.751 & 0.413 \\
\hline 6 & guide & 0.248 & 0.846 & 0.587 & 0.522 & 0.811 & 0.471 \\
\hline 7 & excep & 0.300 & 0.835 & 0.627 & 0.534 & 0.767 & 0.427 \\
\hline 8 & enab & 0.171 & 0.875 & 0.530 & 0.456 & 0.877 & 0.539 \\
\hline
\end{tabular}


the presence of the outcome. This phenomenon is referred to as causal asymmetry and forms one of the core assumptions of QCA (Schneider and Wagemann 2013). Consequently, the opposite has to be investigated (Schneider and Wagemann 2010; Tóth et al. 2015). Table 5 contains the consistency and coverage values for the absence of high levels of negotiation success. Neither the consistency nor coverage values are near those for the presence of the outcome. This result means that a necessary condition for reaching limited levels of negotiation success cannot be identified. Interestingly, consistency values for the presence and absence of conditions toward the absence of the outcome though low are similar. This similarity can be seen as a slight indication for indifference of the approaches toward low levels of negotiation success.

In summary, consistency and coverage values indicate that structured management of negotiations might help achieve higher levels of negotiation success. Even if negotiation management is applied and a high level of negotiation success is not reached, a structured approach does not hurt negotiation performance and cause lower levels of negotiation success.

\subsubsection{Analysis of sufficient conditions}

Contrary to a necessary condition, a sufficient condition allows for different paths to high levels of negotiation success (Schneider and Wagemann 2013). It seems far more likely and logical to expect the presence of a sufficient condition. To analyze for sufficiency, a truth table was constructed, which can be found in Appendix. Configurations of this table that could not be observed or could not be observed with sufficient frequency are labeled "logical remainder" to highlight assumptions made on these (Ragin 2009; Fiss 2011; Werani et al. 2016). Due to the high number of observations, the minimum frequency for a configuration not to be considered a logical remainder was set to $n=20$. This value was extrapolated based on previous publications (Fiss 2011; Tóth et al. 2015; Frösén et al. 2016; Werani et al. 2016). Using this criterion, three logical remainders were observed.

Regarding the minimum threshold for consistency of sufficient conditions, most authors suggest applying 0.75 (Ragin 2009; Tóth et al. 2015; Schneider and Wagemann 2013), while some suggest applying 0.8 (Fiss 2011). Schulze-Bentrop (2013) suggests searching for the largest decline in consistency values of configurations to define the inclusion threshold for a sufficient solution formula. Since, in the truth table, the largest jump in consistency values of configurations is at 0.8 and this value complies with Fiss's (2011) more rigorous criterion, it was chosen as the consistency inclusion threshold. For the minimum threshold of coverage, Thiem and Duşa (2013) suggest applying 0.6 for acceptance as a sufficient condition, which is exceeded by the solution formula for sufficiency identified.

The truth table was constructed for both the presence and the absence of the outcome. While, for the presence of the outcome, a sufficient solution formula could be derived, no configuration surpassed the defined quality criteria for the absence of the outcome. Based on the afore-presented criteria, the Boolean reduction of the 


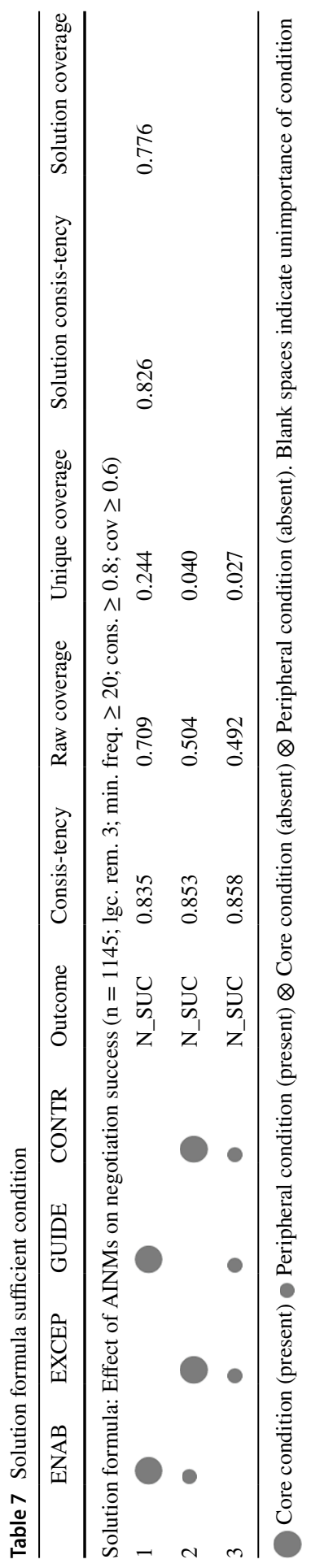


truth table was performed using the Quine-McClusky algorithm in the QCA package in R (Duşa and Thiem 2016). The resulting solution formula can be found in Table 7.

Since three logical remainders were observed, the complex and most parsimonious solutions differ. Elements of the solution formula that are not part of the most parsimonious solution are referred to as peripheral (Schneider and Wagemann 2013; Tóth et al. 2015). While the complex solution does not consider the logical remainders (Schneider and Wagemann 2013), in the most parsimonious solution, assumptions on the logical remainders are made in a way to minimize the solution term (Schneider and Wagemann 2013; Thiem and Duşa 2013).

In line with the afore-discussed descriptive findings, it is noteworthy that only the presence of conditions, namely the approaches to implement negotiation success, enter the solution formula of sufficiency for a high level of negotiation success.

The solution formula ENAB*GUIDE + ENAB*EXCEP*CONTR + EXCEP*GU IDE*CONTR $\rightarrow$ N_SUC can be rearranged to ENAB*(GUIDE + EXCEP*CONTR) + EXCEP $^{*}$ GUIDE*CONTR $\rightarrow$ N_SUC. The significantly higher coverage of paths 1 and 2 compared to that of path 3 underlines the importance of the "enabling" approach. After minimizing the complex solution to the most parsimonious solution, the solution term is ENAB*GUIDE + EXCEP*CONTR $\rightarrow$ N_SUC. This term suggests there are two paths to a high level of negotiation success. Negotiators can achieve a high level of success by combining either the "enabling" approach with the "process guidance" approach or the "manage by exception" approach with the "process control" approach. In line with previous research, these results imply companies should always balance elements of behavior and outcome control (Anderson and Oliver 1987; Cravens et al. 1993; Zoltners et al. 2012). Interestingly, both solution paths combine the approaches previously allocated to the same management style. While ENAB*GUIDE appears to cohere with commitment-based management, EXEP*CONTR resembles a control-oriented management style (Walton 1985; Koopman 1991; Sull 2003).

The two paths identified could also provide an indication of why negotiation management, in practice, does not always unfold its full potential. If negotiation management does not fulfill expectations in practice, this result may be due to partial implementation of the approach combination in either path and an excessive use of direct or indirect levers to influence salespeople. Connecting to path 1, Farmer (1970), Movius and Susskind (2009), and ElShenawy (2010) conclude that training alone does not suffice to achieve high levels of negotiation success. They base this claim on the observation that many companies implement negotiation training but do not connect it sufficiently to real sales situations and even fewer implement dedicated functions to support salespeople during the negotiation process (Ertel 2003). Connecting to path 2 , it has widely been discussed in literature that despite setting up control systems, actual conduct of control often lags behind in practice (Ouchi 1979; Eisenhardt 1985; Anderson and Oliver 1987).

In summary, the solution formula of sufficiency for high negotiation success identified connects with the existing research on management styles and provides a good basis to review and optimize the way companies implement negotiation management within their organization. 


\subsubsection{Variation of the fsQCA setup}

To further underpin these findings, the setup of the fsQCA was modified in different ways. First, we will present the impact on the solution formula from considering the individual success dimensions as an outcome. Second, we will discuss the impact from modifying the calibration of the outcome and the conditions. Third, we will vary the observations included in the fsQCA.

5.2.3.1 fsQCA reflecting individual dimensions of negotiation success Three dimensions of negotiation success were investigated in this study. While the fsQCA could confirm a solution term for sufficiency with two paths, it would be interesting to understand the effect of structured negotiation management toward the effectiveness, efficiency, and satisfaction of the individual success dimensions. To shed light on this question, the fsQCA was re-conducted with the individual success dimensions as outcomes of interest. Since the distribution of responses for all three dimensions are very similar, the same calibration was applied. The same cutoff criteria for sufficiency and coverage of necessary and sufficient conditions were applied. The results are summarized in Table 8.

Similar to the results for the combination of success dimensions, no necessary conditions could be confirmed for any of the individual success dimensions. However, for all three success dimensions solution formulas for sufficiency could be confirmed for all three success dimensions.

Starting the interpretation with the satisfaction dimension of negotiation success, it was found that the same solution formula applies. These results might reflect two different groups of salespeople. First, individuals who enjoy their independence might prefer little company intervention and be more satisfied by being steered following the "enabling" and "guidance" path. Second, salespeople who are less confident and feel more secure when they have to bear less entrepreneurial decisionmaking power might prefer being steered following the "manage by exception" and "process control" path.

For the effectiveness dimension, the solution formula changes to "manage by exception" and "process guidance." This combination is interesting because it differs from the solution term for the combined success dimensions. However, it supports one finding voiced already: It suggests that behavior and outcome control

Table 8 fsQCA results by success dimension

\begin{tabular}{lllll}
\hline Success dimensions & $\begin{array}{l}\text { Necessary } \\
\text { condition }\end{array}$ & Sufficient condition & \\
\cline { 3 - 5 } \cline { 3 - 4 } & & Solution formula & Consistency & Coverage \\
\hline Effectiveness & - & EXCEP*GUIDE $\rightarrow$ N_SUCC & 0.823 & 0.615 \\
Efficiency & - & EXCEP*CONTR + & 0.803 & 0.760 \\
& & EXCEP*GUIDE + & & \\
Satisfaction & - & ENAB*GUIDE*CONTR $\rightarrow$ N_SUCC & & \multirow{2}{*}{ ENABUIDE + } \\
& & EXCEP*CONTR $\rightarrow$ N_SUCC & 0.815 & 0.778 \\
\hline
\end{tabular}


levers should be combined to manage negotiations. Finally, the solution formula for the efficiency dimension combines three paths. Without detailed discussion of each, all three paths again suggest combining behavior and outcome control levers to steer negotiations.

5.2.3.2 Variation of calibration To solidify the results, the calibration of the success dimension was also tested. As mentioned, while variating the points of full inclusion and exclusion for set membership by 20 percent does not change the findings, adjusting the position of the crossover point does have an effect. If the crossover point is increased by more than 10 percent, neither a necessary nor a sufficient condition can be accepted. This result, however, is to be expected, since the more observations transferred from set membership to non-membership, the fewer cases remain to explain inclusion.

The calibration of the four approaches was also altered. Lowering the point of exclusion to "does not apply at all" and increasing the point of inclusion to "fully applies" for full set membership results in the same solution formula ENAB $*$ GUIDE + EXCEP $*$ CONTR $\rightarrow$ N_SUC and increased consistency value of 0.883 and almost stable coverage of 0.668 , respectively.

5.2.3.3 Variation of responses included in fsQCA The majority of respondents did not claim to apply all four approaches in parallel. However, to limit the impact of potential bias from a confirmative answering behavior, the fsQCA was re-conducted excluding all cases where respondents claimed that all four approaches at least "mostly apply." This step reduced the number of observations to 991. In this setup, no necessary condition could be found, but the solution formula for sufficiency changes to ENAB*GUIDE $\rightarrow$ N_SUC with a solution consistency of 0.805 and a solution coverage of 0.647 . This result is identical to the first path in the solution formula as found for all respondents.

As a summary to all variations, the overarching observations, that only the presence (not the absence) of structured negotiation management supports any form of higher negotiation success, remains. It, however, also underlines that different targets and likely different situations result in different solution formulas, which calls for further investigation into these directions.

\section{Conclusions, limitations, and outlook}

This study attempts to investigate which actions companies can take to implement successful negotiation management in their organization. Based on the four approaches to negotiation management "enabling," "manage by exception," "process guidance," and "process control" introduced by Voeth and Mayer (2018), the effects on negotiation success of each approach and all possible combinations of the approaches have been assessed. As a general finding, it can be concluded that applying any of the discussed approaches to negotiation management seems to support higher levels of negotiation success than if negotiations are not actively managed. 
The four approaches are identified as one driver but are probably not the only drivers for success. Therefore, future research should investigate which other drivers influence negotiation success. Once there is more clarity on the drivers, quantitative research methods should be used to draw confirmative conclusions. Drivers that similarly influence negotiation success might include the situational environment a deal is negotiated in. This situational impact has been widely addressed for salesforce control strategies in the literature (Dubinsky and Ingram 1984; Jaworski 1988; Cannon and Perrault Jr. 1990; Krafft 1999; Dubinsky et al. 2001; Ross and Robertson 2003; Anderson and Onyemah 2006; Verbeke et al. 2011). On the other hand, Cravens et al. (1993) and Zoltners et al. (2012) suggest that other factors such as the motivation of salespeople serve as strong drivers of sales success.

Due to the assumed causal asymmetry and equifinality, the success effect of the approaches was assessed using fsQCA. As was expected, no necessary condition for a high level of negotiation success could be identified, but one solution formula for sufficiency was derived. Even though three logical remainders were observed and one could re-conduct the analysis on a sample comprising all possible configurations, the results seem valid, as descriptive and qualitative methods point in the same direction. These results can be understood as confirming the first research question, which asked whether actively addressing structured negotiation management had a positive effect on negotiation success. In this sense, the results of the study support negotiation management research and efforts taken by companies to implement negotiation management.

Contrary to that, the study was not able to identify a necessary or sufficient condition resulting in low levels of negotiation success. This result confirmed the assumed causal asymmetry. The multiple paths in the solution formula support the assumption of an equifinal nature, and the choice of the research method is confirmed expost. This result is also highly plausible because, even though structured negotiation management seems to support negotiation success, there may be many different reasons for a low level of negotiation success besides not applying negotiation management. Likewise, different forms of negotiation management might similarly support more successful negotiations.

The parsimonious form of the sufficient solution formula comprises two paths to high levels of negotiation success. It suggests combining the "enabling" approach with the "process guidance" approach or the "manage by exception" approach with the "process control" approach. These two paths seem congruent with management styles previously presented by Walton (1985), Koopman (1991), and Sull (2003). Empowering salespeople to develop commitment and excel in negotiations following an intrinsic motivation supports high levels of negotiation success. Likewise, where a control strategy is chosen, higher levels of negotiation success seem achievable based on the application of systematic negotiation management. In this case, the findings even suggest that a combination of outcome and behavior control promises the highest chances of achieving negotiation success. This finding was confirmed by different variations of the fsQCA setup. The assertion that combining behavior and outcome control measures leads to better negotiation outcomes goes a step further than previous research, which merely reported that, in practice, typically combinations of outcome and behavior control were typically observed (Anderson 
and Oliver 1987; Cravens et al. 1993). In doing so, the study results provide practical guidance for companies implementing negotiation management on what to do to realize higher negotiation success.

Further research should investigate how companies following different negotiation management approaches operationalize these outcome and behavior control levers. Since many levers can be used in different approaches to negotiation management, they will most likely be operationalized differently depending on the implementation strategy. Insight into how operationalization impacts negotiation success would provide more guidance to practitioners.

Another question that has not been answered but would be very interesting is which of the two paths should be chosen in a specific situation or environment. The impact of environmental factors has been underlined by many researchers, which implies that the effect of situational factors on the success of negotiation management approaches remains a question for further research. This is in line with the findings from variating the fsQCA and the conclusion that paths in the solution formula change based on what the target is.

One limitation lies in the nature of respondents. As salespeople were surveyed about their own performance, there is a high likelihood they overestimated their competence. To account for this factor, sales managers were also interviewed, and no significant difference in the answering behavior could be found. Another bias may lie in the fact that each respondent reflected on their own company, which implies that objectivity of evaluations might vary from respondent to respondent. While previous research (Huthwaite 2009) chose to compare negotiation performance from an external perspective, we think that taking the internal view provides additional depth that outweighs this caveat. Beyond that, a large amount of demographic information was collected on the responding companies to account for the limitation that the sample is not fully randomized. This compromise had to be accepted, since the information required is not openly available, and utilizing the Lightspeed B2B panel provided the best opportunity to access sales practitioners. Respondents were presented with detailed descriptions and explanations on how to interpret the four implementation approaches and were asked to indicate the extent to which these apply. For this first study on the success effect of structured negotiation management, we had to accept this unidimensional scale. A multi-item scale reflecting a precise definition of negotiation management would require more transparency on the operationalization of influence levers following a specific approach. This goes beyond the analysis of Voeth and Mayer (2018) and is difficult to achieve given the countless nuances of how companies could make use of the 27 levers as part of the four implementation approaches.

Altogether, this study provides evidence that negotiation management has a generally positive effect on negotiation success, provides evidence for the relevance the research field, and gives practitioners rationale for installing negotiation management within their sales organizations. It also serves as an initial attempt to bridge the gap between the research on negotiation management and salesforce control and raises further questions for research. Lastly, the paths identified to support high levels of negotiation success provide actionable results for companies seeking to review, optimize, or install negotiation management in their organizations. 


\section{Appendix: Truth table for sufficient condition}

\begin{tabular}{llllllll}
\hline Configuration ENAB EXCEP GUIDE CONTR OUTCOME $\mathrm{n}$ & $\begin{array}{l}\text { Consistency } \\
\text { for presence }\end{array}$ fonsistency \\
for absence
\end{tabular}

\begin{tabular}{|c|c|c|c|c|c|c|c|c|}
\hline \multicolumn{9}{|c|}{ Truth table main model } \\
\hline 16 & 1 & 1 & 1 & 1 & 1 & 444 & 0.865 & 0.189 \\
\hline 15 & 1 & 1 & 1 & 0 & 1 & 113 & 0.851 & 0.320 \\
\hline 8 & 0 & 1 & 1 & 1 & 1 & 31 & 0.848 & 0.496 \\
\hline 11 & 1 & 0 & 1 & 0 & 1 & 38 & 0.827 & 0.487 \\
\hline 12 & 1 & 0 & 1 & 1 & 1 & 116 & 0.824 & 0.322 \\
\hline 14 & 1 & 1 & 0 & 1 & 1 & 46 & 0.820 & 0.456 \\
\hline 13 & 1 & 1 & 0 & 0 & 0 & 66 & 0.791 & 0.423 \\
\hline 10 & 1 & 0 & 0 & 1 & 0 & 35 & 0.773 & 0.519 \\
\hline 4 & 0 & 0 & 1 & 1 & 0 & 30 & 0.772 & 0.555 \\
\hline 9 & 1 & 0 & 0 & 0 & 0 & 29 & 0.742 & 0.587 \\
\hline 5 & 0 & 1 & 0 & 0 & 0 & 25 & 0.685 & 0.659 \\
\hline 2 & 0 & 0 & 0 & 1 & 0 & 26 & 0.639 & 0.678 \\
\hline 1 & 0 & 0 & 0 & 0 & 0 & 103 & 0.438 & 0.665 \\
\hline 6 & 0 & 1 & 0 & 1 & $?$ & 13 & 0.760 & 0.737 \\
\hline 7 & 0 & 1 & 1 & 0 & $?$ & 16 & 0.757 & 0.715 \\
\hline 3 & 0 & 0 & 1 & 0 & $?$ & 14 & 0.739 & 0.732 \\
\hline
\end{tabular}

Author contributions All authors contributed to the study conception and design. Material preparation, data collection and analysis were performed by Markus Mayer. The first manuscript was written by Markus Mayer and all authors commented on previous versions of the manuscript. All authors read and approved the final manuscript.

Funding Open Access funding enabled and organized by Projekt DEAL.

\section{Declarations}

Conflict of interest The authors declare that they have no conflict of interest.

Open Access This article is licensed under a Creative Commons Attribution 4.0 International License, which permits use, sharing, adaptation, distribution and reproduction in any medium or format, as long as you give appropriate credit to the original author(s) and the source, provide a link to the Creative Commons licence, and indicate if changes were made. The images or other third party material in this article are included in the article's Creative Commons licence, unless indicated otherwise in a credit line to the material. If material is not included in the article's Creative Commons licence and your intended use is not permitted by statutory regulation or exceeds the permitted use, you will need to obtain permission directly from the copyright holder. To view a copy of this licence, visit http://creativecommons.org/licen ses/by/4.0\%. 


\section{References}

Alexander JF, Schul PL, McCorkle DE (1994) An assessment of selected relationships in a model of the industrial marketing negotiation process. J Pers Sell Sales Manag 14(3):25-41

Allred KG, Mallozzi JS, Matsui F, Raia CP (1997) The influence of anger and compassion on negotiation success. Organ Behav Hum Decis Process 70(3):175-187

Amantullah ET, Tinsley CH (2013) Ask and ye shall receive? How gender and status moderate negotiation success. Negot Confl Manag Res 6(4):253-272

Anderson RE, Huang W-Y (2006) Empowering salespeople: personal, managerial, and organizational perspectives. Psychol Mark 23(2):139-159

Anderson E, Oliver RL (1987) Perspectives on behavior-based versus outcome-based salesforce control systems. J Mark 51(4):76-88

Anderson E, Onyemah V (2006) How right should the customer be? Harv Bus Rev 87(7/8):59-67

Burkardt N, Lamb BL, Taylor JG (1998) Desire to bargain and negotiation success: lessons about the need to negotiate from six Hydropower disputes. Environ Manag 22(6):877-886

Cannon JP, Perrault WD (1990) Buyer-Seller relationships in business markets. J Mark Res 36:439-460

Cravens DW, Ingram TN, LaForge RW, Young CE (1993) Behavior-based and outcome-based salesforce control systems. J Mark 57(4):47-59

Darmon RY, Martin XC (2011) A new conceptual framework of sales force control systems. J Pers Sell Sales Manag 31(3):297-310

De Dreu CKW (2004) Motivation in negotiation: a social psychological analysis. In: Gelfand MJ, Brett JM (eds) The handbook of negotiation and culture. Standford University Press, Standford, pp $114-135$

Dubinsky AJ, Ingram TN (1984) From selling to sales management: a developmental model. J Consum Mark 1(3):43-52

Dubinsky AJ, Jolson MA, Anderson RE, Metha R (2001) Salesperson failure: a case of sales manager risk and responsibility. Risk Manag 3(2):17-28

Duşa A, Thiem A (2016) QCA: qualitative comparative analysis. R Package Version 2:5

Eidenmüller H (2012) Die Rolle von Verhandlungsmanagement und Mediation in der Juristenausbildung. In: Hagen H (ed) Rechtsgestaltung-Rechtskritik-Konkurrenz von Rechtsordnungen Neue Akzente für die Juristenausbildung. Nomos, Baden-Baden, pp 356-364

Eisenhardt KM (1985) Control: organizational and economic approaches. Manage Sci 31(2):134-149

ElShenawy E (2010) Does negotiation training improve negotiators' performance? J Eur Ind Train 34(3):192-210

Ertel D (2003) Turning negotiation into a corporate capability. In: Press HBS (ed) Harvard business review on negotiation and conflict resolution. Harvard Business School Press, Boston, pp 101-128

Farmer D (1970) Training in the skills of negotiation. Ind Commer Train 2(11):513-516

Fells R (2013) Negotiation success: an application of the Halpert et al path model. Negot Confl Manag Res 6(2):133-150

Fisher R, Ury W, Patton BM (2012) Getting to yes. Negotiating an agreement without giving in. Random House Business Books, London

Fiss PC (2011) Building better causal theories: a fuzzy set approach to typologies in organization research. Acad Manag J 54(2):393-420

Frösén J, Luoma J, Jaakola M, Tikkanen H, Aspara J (2016) What counts versus what can be counted: the complex interpay of market orientation and marketing performance measurement. J Mark 80:60-78

Gaibulloev K, Sandler T (2009) Hostage taking: determinants of terrorist logistical and negotiation success. J Peace Res 46(6):739-756

Gates S (2006) Time to take negotiation seriously. Ind Commer Train 38(5):283-241

Geiger I (2017) A model of negotiation issue-based tactics in business-to-business sales negotiations. Ind Mark Manag 64:91-106

Giangreco A, Peccei R (2005) The nature and antecedents of middle manager resistance to change. Evidence from an Italian context. Int J Hum Resour Manag 16(10):1812-1829

Goertz G (2006) Assessing the trivialness, relevance, and relative importance of necessary or sufficient conditions in social science. Stud Comp Int Dev 41(2):88-109

Grewal R, Lilien GL, Bharadwaj S, Jindal P, Kayande U, Lusch RF et al (2015) Business-to-business buying. Challenges and opportunities. Cust Needs Solut 2(3):193-208 
Halpert JA, Stuhlmacher AF, Crenshaw JL, Litcher CD, Bortel R (2010) Paths to negotiation success. Negot Confl Manag Res 3(2):91-116

Hayter CS (2010) In search of the profit-maximizing actor: motivations and definitions of success from nascent academic entrepreneurs. J Technol Transf 36:340-352

Herbst U (2009) Verhandlungsmanagement als betriebswirtschaftlicher Erfolgsfaktor. In: Ralph B (ed) Weltwirtschaft 2010, Trends und strategien. Springer, Berlin, Heidelberg, pp 181-195

Homburg C, Schäfer H, Schneider J (2012) Sales excellence. Systematic sales management. Springer, Berlin

Huthwaite / IACCM (2009) Improving corporate negotiation performance. https://s3.eu-central-1. amazonaws.com/iaccmportal/resources/files/7596_improvingcorporatenegotiationperformace.pdf. Accessed 5 Sep 2020

Imai L, Gelfand MJ (2007) Culturally intelligent negotiators: The impact of cq on intercultural negotiation effectiveness. Acad Manag Proc 1:1-6

Jaworski BJ (1988) Toward a theory of marketing control: Environmental context, control types and consequences. J Mark 52:23-39

Keeney RL, Raiffa H, Meyer RF (2003) Decisions with multiple objectives. Preferences and value tradeoffs. Digital printing. University Press, Cambridge

Koopman PL (1991) Between control and commitment: management and change as the art of balancing. Leadersh Org Dev J 12(5):3-7

Krafft M (1999) An empirical investigation of the antecedents of sales force control systems. J Mark 63:120-134

Kray LJ, Thompson L (2005) Gender stereotypes and negotiation performance: an examination of theory and research. Res Organ Behav 26:103-182

Kurtzberg TR, Dunn-Jensen LM, Matsibekker CLZ (2005) Multi-party e-negotiations: agents, alliances, and negotiation success. Int J Conf Manag 16(3):245-264

Lewicki RJ, Saunders DM, Barry B (2014) Negotiation, 7th edn. McGraw-Hill Education, New York

Lightspeed (2017) B2B Panels. Lightspeed LLC. http://www.lightspeedresearch.com/sample-audiences/ business-to-business-panels/. Accessed 05 Nov 2017

Lim RG, Carnevale PJD (1990) Contingencies in the mediation of disputes. J Pers Soc Psychol 58(2):259-272

Mahaney RC, Lederer AL (2011) An agency theory explanation of project success. J Comput Inform Syst 51(4):102-113

Melzer P, Schoop M (2016) The effects of personalized negotiation training on learning and performance in electronic negotiations. Group Decis Negot 25:1189-1210

Movius H, Susskind L (2009) Built to win. Creating a world-class negotiating organization. Harvard Business Press, Boston

Nyhart JD, Samarasan DK (1989) The elements of negotiation management: using computers to help resolve conflicts. Negot J 5(1):43-62

O'Connor KM, Arnold JA, Burris ER (2005) Negotiators' bargaining histories and their effects on future negotiation performance. J Appl Psychol 90(2):350-362

Ouchi WG (1979) A conceptual framework for the design of organizational control mechanisms. Manag Sci 25(9):833-848

Ragin CC (1987) The comparative method: Moving beyond qualitative and quantitative strategies. University of California Press, London

Ragin CC (2000) Fuzzy-set social science. University of Chicago Press, London

Ragin CC (2006) Set relations in social research: evaluating their consistency and coverage. Polit Anal $14: 291-310$

Ragin CC (2007) Fuzzy sets: calibration versus measurement. In: Chi M (ed) Methodology volume of Oxford handbooks of political science 2. Springer, Berlin

Ragin CC (2008a) Qualitative comparative analysis and fuzzy sets. Sage, London

Ragin CC (2008b) Redesigning social inquiry. NCRM Research Methods Festival, Oxford, p 2008

Ragin CC (2009) Qualitative comparative analysis using fuzzy sets (fsQCA). In: Charles CR, Benoît $\mathrm{R}$ (eds) Configurational comparative methods. Qualitative comparative analysis and related techniques, vol. 51. Sage, London, pp 87-122

Ragin CC, Rihoux B (eds) (2009) Configurational comparative methods. Qualitative s. Springer, Berlin

Ross WT, Robertson DC (2003) A typology of situational factors: impact on salesperson decision-making about ethical issues. J Bus Ethics 46(3):213-234 
Schneider CQ, Wagemann C (2010) Standards of good practice in qualitative comparative analysis (QCA) and fuzzy-sets. Comp Sociol 9(3):397-418

Schneider CQ, Wagemann C (2013) Set-theoretic methods for the social sciences. A guide to qualitative comparative analysis. Cambridge University Press, Cambridge

Schoop M, Köhne F, Ostertag K (2010) Communication quality in business negotiations. Group Decis Negot 19:193-209

Schulze-Bentrop C (2013) Qualitative comparative analysis (QCA) and configurational thinking in management studies. Peter Lang, Frankfurt am Main

Simon H, Bilstein FF, Luby F (2006) Manage for profit, not for share. A guide to greater profitability in highly contested markets. Harvard Business School Press, London

Sull D (2003) Managing by commitments. In: Harvard Business Review

Thiem A, Duşa A (2013) Qualitative comparative analysis with R. A user's guide. Springer, New York (Springer Briefs in political science)

Thompson L (1990) The influence of experience on negotiation performance. J Exp Soc Psychol 26:528-544

Thompson LL (2005) The mind and heart of the negotiator, 3rd edn. Pearson/Prentice Hall, Upper Saddle River, NJ

Tóth Z, Thiesbrummel C, Henneberg SC, Naudé P (2015) Understanding configurations of relational attractiveness of the customer firm using fuzzy set QCA. J Bus Res 68:723-734

Underdal A (1983) Causes of negotiation “failure.” Eur J Polit Res 11:183-195

Verbeke W, Dietz B, Verwaal E (2011) Drivers of sales performance: a contemporary meta-analysis. Have sales people become knowledge brokers? J Acad Mark Sc 39:407-428

Voeth M, Herbst U (2015) Verhandlungsmanagement. Planung, Steuerung und Analyse. Schäffer-Poeschel-Verlag, Stuttgart

Voeth M, Mayer M (2018) Ansätze für die Institutionalisierung von Verhandlungsmanagement im Vertrieb. Die Unternehmung 72(1):87-106

Voeth M, Herbst U, Sattler S (2014) Sind Verhandlungen wirklich Chefsache? Die Betriebswirtschaft 74(1):9-40

Walton RE (1985) From control to commitment in the workplace. In: Harvard Business Review

Werani T, Freiseisen B, Martinek-Kuchinka P, Schauberger A (2016) How should successful business models be configured? Results from an empirical study in business-to-business markets and implications for the change of business models. J Bus Econ 86:579-608

Williams BC, Plouffe CR (2007) Assessing the evolution of sales knowledge: A 20-year content analysis. Ind Mark Manag 36:408-419

Zetik DC, Stuhlmacher AF (2002) Goal setting and negotiation performance: a meta-analysis. Group Process Intergroup Relat 5(1):35-52

Zoltners AA, Prabhakant S, Lorimer SE (2012) Breaking the sales force incentive addiction: a balanced approach to sales force effectiveness. J Pers Sell Sales Manag 32(2):171-186

Publisher's Note Springer Nature remains neutral with regard to jurisdictional claims in published maps and institutional affiliations. 